\title{
La reducción en el ISD por la adquisición de la vivienda habitual del causante: análisis estatal, autonómico y foral
}

\section{Analysis of the Spanish reduction in the Inheritance and Gift Tax for the acquisition mortis causa of the main residence of the deceased}

\author{
Irene Rovira Ferrer \\ Universitat Oberta de Catalunya (España) \\ ORCID: https://orcid.org/0000-0003-0031-6892 \\ iroviraf@uoc.edu
}

\begin{abstract}
NOTA BIOGRÁFICA
Irene Rovira es Licenciada en Derecho (Universitat Pompeu Fabra, 2006) y Doctora en Sociedad de la Información y el conocimiento, especialidad en Derecho Financiero y Tributario (Universitat Oberta de Catalunya, 2010). Actualmente es Profesora Agregada de Derecho Financiero y Tributario en la Universitat Oberta de Catalunya y sus principales líneas de investigación se circunscriben en los derechos y deberes de los obligados tributarios, la imposición directa y la fiscalidad autonómica y local.
\end{abstract}

\section{RESUMEN}

El objetivo principal del presente trabajo es el análisis de la reducción prevista en la base imponible del ISD en el caso de la adquisición mortis causa de la vivienda habitual del causante, tanto a nivel estatal como autonómico y foral. Así, además de valorar su viabilidad y estudiar las precisiones que derivan de una realidad compleja, se analizarán los diferentes conflictos normativos que aparecen y que, en algún caso, llegan a ser susceptibles de inconstitucionalidad, acabando con algunas propuestas de mejora para su reformulación.

\section{PALABRAS CLAVE}

Impuesto sobre Sucesiones y Donaciones; vivienda habitual; reducción de la base imponible.

\begin{abstract}
The main scope of this study is the analysis of the reduction in the tax base of the Inheritance and Gift Tax for the acquisition mortis causa of the main residence of the deceased. Apart from evaluating its viability, State and regional regulations will be analysed, trying to highlight the different problems encountered and questioning the position of Spain's Supreme Court in some aspects. Finally, a new formulation of its reduction will be provided.
\end{abstract}

\section{KEYWORDS}

Inheritance and Gift Tax; main residence; reduction in the tax base.

\section{SUMARIO}

1. INTRODUCCIÓN. 2. LA REGULACIÓN ESTATAL DE LA REDUCCIÓN. 3. LA REGULACIÓN AUTONÓMICA Y FORAL DE LA REDUCCIÓN. 4. EL CONCEPTO DE VIVIENDA HABITUAL DEL CAUSANTE. 5. LOS SUJETOS QUE TIENEN DERECHO A LA REDUCCIÓN. 6. EL REQUISITO DE CONVIVENCIA. 7. EL MANTENIMIENTO DE LA VIVIENDA EN EL PATRIMONIO DEL ADQUIRENTE. 8. CONCLUSIONES. 9. BIBLIOGRAFÍA. 


\section{INTRODUCCIÓN}

Una de las figuras más conflictivas de nuestro sistema tributario (tanto por lo que respecta a su propia procedencia como a su configuración) es el Impuesto sobre Sucesiones y Donaciones (ISD), el cual, de titularidad estatal, se encuentra regulado por la Ley 29/1987, de 18 de diciembre, del Impuesto sobre Sucesiones y Donaciones (LISD), y el Reglamento del Impuesto sobre Sucesiones y Donaciones (RISD), aprobado por el Real Decreto 1629/1991, de 8 de noviembre.

No obstante, tanto las Diputaciones forales de los territorios históricos del País Vasco como la Comunidad Foral de Navarra tienen reconocidas, entre otras, competencias normativas sobre el mismo (ya que, de conformidad con el art. 25 del Concierto económico con el País Vasco -aprobado por la Ley 12/2002, de 23 de mayo- y el art. 31 del Convenio económico con Navarra -aprobado por la Ley 28/1990, de 26 de diciembre-, tiene la consideración de tributo concertado de normativa autónoma), del mismo modo que las tienen el resto de Comunidades Autónomas (CCAA) de régimen común (por cuanto, como señala el art.11.d) de la Ley Orgánica 8/1980, de 22 de septiembre, de Financiación de las Comunidades Autónomas (LOFCA) y desarrolla la Ley 22/2009, de 18 de diciembre, por la que se regula el sistema de financiación de las Comunidades Autónomas de régimen común y Ciudades con Estatuto de Autonomía y se modifican determinadas normas tributarias, constituye un tributo cedido a las mismas).

Sin embargo, mientras que los territorios forales tienen plena capacidad para configurar los elementos principales del Impuesto ${ }^{1}$, en el resto de CCAA se encuentra limitada a determinados aspectos, entre los cuales se encuentran, como señala el art. 48 de la Ley 22/2009, las reducciones de la base imponible (ya sea creando reducciones propias que respondan a circunstancias de carácter económico o social propias de la autonomía -caso en el que se aplicarán con posterioridad a las estatales- o mejorando las del Estado -supuesto en el que las sustituirán-).

De este modo, si las CCAA ejercen tales competencias, procederá la aplicación su normativa cuando el rendimiento ISD les resulte cedido conforme a los pertinentes puntos de conexión, aunque, si no hubieran adoptado ninguna disposición al respecto, también se les cederá el rendimiento pero se aplicará la normativa estatal (arts. 27 y 53 de la Ley 22/2009).

Así pues, era importante realizar tales precisiones porque el estudio de una de las reducciones de la base imponible del ISD que contempla la normativa estatal (y que se ha desarrollado mayoritariamente a nivel autonómico) es el objeto del presente trabajo, concretamente la prevista por la adquisición mortis causa de la vivienda habitual del causante.

Y es que su discutible configuración y la parquedad de las previsiones estatales han dado lugar a un panorama confuso con posicionamientos contradictorios por parte de la Dirección General de Tributos (DGT) y los propios tribunales, contexto en el que deben añadirse las diversas singularidades que han introducido la mayor parte de autonomías (cuestionables en algunos casos desde el punto de vista constitucional e incluso del propio Derecho de la Unión Europea -UE-).

De este modo, a continuación, se abordará su análisis en profundidad, estudiando las distintas normativas al respecto, clarificando su aplicación en aquellas cuestiones no expresamente previstas por la regulación y detectando los diferentes aspectos problemáticos que se plantean. Asimismo, partiendo de estas consideraciones, se valorará su propia procedencia y la de sus distintos elementos, aportando propuestas de mejora para su reformulación y óptima configuración.

Y es que no hay que olvidar que la relevancia de la reducción aquí estudiada no es menor, por cuanto, aparte de la gran cuantía que puede liberar de imposición ${ }^{2}$, conlleva otras importantes ventajas respecto al pago de la cuota tributaria derivada de la transmisión de la mencionada vivienda (concretamente, en relación con su aplazamiento -que podrá ser de 5 años-y fraccionamiento - de 10 pagos semestrales transcurrido el plazo anterior-).

\footnotetext{
1 No obstante, y aunque su capacidad se entiende completa por regla general, no es ilimitada, sino que se encuentra supeditada a determinados principios y limitaciones como son, además de los establecidos por la Constitución (CE) con base en su supremacía, los previstos en los arts. 2 a 4 del Concierto económico con el País Vasco y 2 del Convenio económico con Navarra. Además, no hay que olvidar los límites derivados de los tratados o convenios internacionales suscritos por el Estado, así como los directamente procedentes de la UE.

2 Al respecto, y aunque la LISD fije una reducción del $95 \%$ del valor de la vivienda, algunas CCAA lo han incrementado hasta el $100 \%$, como es el caso, como se verá, de las Islas Baleares (art. 23 del Decreto Legislativo 1/2014, de 6 de junio, por el que se aprueba el Texto Refundido de las Disposiciones Legales de la Comunidad Autónoma de las Illes Balears en Materia de Tributos Cedidos por el Estado).
} 


\section{LA REGULACIÓN ESTATAL DE LA REDUCCIÓN}

La incorporación en la regulación del ISD de la reducción aquí estudiada se llevó a cabo por el Real Decreto-Ley 7/1996, de 7 de junio, sobre medidas urgentes de carácter fiscal y de fomento y liberalización de la actividad económica, cuya Exposición de motivos manifestó que con la misma se pretendía «aliviar el coste fiscal derivado de la transmisión mortis causa (...) de la vivienda habitual, cuando dicha transmisión se efectuase en favor de ciertas personas allegadas al fallecido». Por consiguiente, parece que la justificación de su adopción debe buscarse en la finalidad extrafiscal de garantizar el derecho a disfrutar de una vivienda digna y adecuada contemplado en el art. 47 de la CE, del mismo modo que, al mencionar las «personas allegadas», podría alegarse la protección social, económica y jurídica de la familia que requiere el art. 39 de la misma.

Y en este punto procede destacar que, en ambos casos, se trata de fines de interés general, constitucionalmente perseguidos, capaces de justificar el beneficio fiscal que conllevan, ya que, como ha señalado expresamente el TC, las excepciones al deber general de contribuir pueden venir fundamentadas «por motivos de política económica o social, para atender al mínimo de subsistencia, por razones de técnica tributaria, etc. $\aleph^{3}$ o incluso, como ha reconocido expresamente, para proteger la institución familiar ${ }^{4}$.

Actualmente, su regulación se contempla en el art. 20.2.c) de la LISD, donde se señala que una de las reducciones que podrá aplicarse a la base imponible para obtener la base liquidable en las adquisiciones mortis causa gravadas por el Impuesto es la relativa a la vivienda habitual del causante, siempre que la misma sea objeto de adquisición por parte de su cónyuge, ascendientes o descendientes, o bien por parte de un pariente colateral mayor de 65 años que hubiese convivido con el mismo durante los dos años anteriores a su fallecimiento.

En concreto, como señala el propio precepto y desarrolló el epígrafe 1.4.d) de la Resolución 2/1999, de 23 de marzo, de la DGT, relativa a la aplicación de las reducciones en la base imponible del Impuesto sobre Sucesiones y Donaciones, en materia de vivienda habitual y empresa familiar, el coste de la vivienda podrá reducirse en un $95 \%$ de su valor una vez deducidas las cargas o gravámenes de naturaleza perpetua, temporal o redimible que aparezcan directamente establecidos sobre la misma disminuyendo su valor, así como la parte proporcional de deudas y gastos generales que formen parte del caudal relicto.

Así, cada adquirente podrá aplicarse la mencionada reducción en la parte proporcional al valor de la vivienda habitual que se integre en su base imponible (el valor neto), de acuerdo con el derecho sobre la misma que se les transmita (propiedad, nuda propiedad, usufructo, etc. -es decir, practicándose la reducción sobre el valor del derecho relativo a la vivienda que vayan a adquirir-).

Sin embargo, la normativa estatal señala un doble límite para su aplicación: por una parte, estableciendo que la reducción procederá con el máximo de 122.606,47€ para cada sujeto pasivo que tenga derecho a la misma y, por otra parte, condicionando su viabilidad a que la vivienda se mantenga en el patrimonio de los adquirentes durante los diez años siguientes a la defunción del causante (salvo que fallezcan dentro de ese plazo).

Además, respecto al abono de la cuota del Impuesto derivada de dicha transmisión, los sujetos que tengan derecho a la misma también podrán beneficiarse de las facilidades especiales de pago que prevé el art. 39 de la LISD (las cuales afectarán a la parte proporcional de la deuda tributaria que corresponda al valor de la vivienda transmitida en relación con el total del caudal hereditario de cada uno de los causahabientes), punto en el que podrá aplazarse su ingreso durante los cinco años siguientes al día en el que termine el plazo voluntario para su pago (supuesto en el que existirá la obligación de constituir caución suficiente aunque no procederá el abono de intereses durante el período de aplazamiento) y, una vez finalizados estos cinco años, podrá fraccionarse en diez plazos semestrales con las mismas condiciones y requisitos (si bien, en este caso, procederá el abono del interés legal del dinero durante el tiempo de fraccionamiento).

\footnotetext{
3 En este punto, véase, entre otras, las SSTC 96/2002, de 25 de abril, o 57/2005, de 14 de marzo.

4 Al respecto, y aunque el TC haya señalado que el art. 39 de la CE no obliga a los poderes públicos a prestar dicha protección de una determinada manera (ni «a través de medidas de una determinada naturaleza» -STC 214/1994, de 14 de julio- ni incluso «a través del sistema tributario»-ATC 289/1999, de 30 de noviembre-, sí que ha reconocido la legitimidad de medidas fiscales orientadas a tal efecto (véase, entre otras, la STC 209/1988, de 10 de noviembre).
} 


\section{LA REGULACIÓN AUTONÓMICA Y FORAL DE LA REDUCCIÓN}

Como se ha señalado, el art. 48 de la Ley 22/2009 reconoce a las CCAA de régimen común competencias normativas en relación con determinados aspectos del ISD, entre los que se encuentran las reducciones de la base imponible. Así, por lo que respecta a la reducción aquí estudiada, se encuentran habilitadas para mejorar la regulación estatal, ya sea ampliándola o contemplando condiciones más beneficiosas para los sujetos pasivos.

$\mathrm{Y}$, de hecho, así ha sido llevado a cabo por la mayor parte de las autonomías, excepto en el caso de Castilla y León, Castilla-La Mancha, Extremadura y la Región de Murcia (ya que, como se ha señalado, esta capacidad normativa es del todo potestativa).

En concreto, las principales diferencias respecto a la normativa estatal que se han contemplado han sido para ampliar los sujetos que podrán tener acceso a la misma, para incrementar el porcentaje de reducción, para aumentar el límite cuantitativo al respecto y, por último, para reducir el tiempo requerido de mantenimiento de la vivienda en el patrimonio del adquirente.

Por su parte, en relación con la normativa foral, Navarra no ha adoptado ninguna previsión al respecto, aunque sí que lo han hecho los tres territorios históricos forales del País Vasco con diferencias substanciales respecto a la estatal. En tales casos, se ha decidido no supeditar la aplicación de la reducción a ninguna relación de parentesco con el causante sino a la convivencia efectiva con el mismo durante los dos años anteriores a su fallecimiento, eliminando, al mismo tiempo, la obligación de mantener en la vivienda en el patrimonio del adquirente durante un cierto período de tiempo.

A grandes rasgos, las características de la vigente regulación autonómica y foral al respecto se resumen a continuación:

CUADRO 1. LAS PRINCIPALES CARACTERÍSTICAS DE LA REDUCCIÓN AUTONÓMICA Y FORAL

\begin{tabular}{|c|c|c|c|c|}
\hline Normativa & Sujetos & Porcentaje & $\begin{array}{l}\text { Límite cuantitativo } \\
\text { individual }\end{array}$ & $\begin{array}{c}\text { Mantenimiento } \\
\text { en el } \\
\text { patrimonio } \\
\text { del causante }\end{array}$ \\
\hline Estado $^{a}$ & $\begin{array}{l}\text { Cónyuge, ascendientes, des- } \\
\text { cendientes o colaterales con- } \\
\text { vivientes con el causante ma- } \\
\text { yores de } 65 \text { años. }\end{array}$ & $95 \%$ & $\begin{array}{c}122.606,47 € \text { por } \\
\text { cada sujeto pasivo. }\end{array}$ & 10 años \\
\hline Andalucía $^{b}$ & $\begin{array}{l}\text { Se añaden las parejas de he- } \\
\text { cho y personas que realicen o } \\
\text { sean objeto de un acogimien- } \\
\text { to familiar permanente y guar- } \\
\text { da con fines de adopción. }\end{array}$ & $\begin{array}{l}\text { Del } 95 \% \text { al } 100 \% \\
\text { en función del valor } \\
\text { real neto del inmueble } \\
\text { en la base imponible } \\
\text { de cada sujeto pasivo. }\end{array}$ & No & 3 años \\
\hline Aragón $^{c}$ & Igual que la normativa estatal. & $100 \%$ & $\begin{array}{l}200.000 € \text { por cada } \\
\text { sujeto pasivo. }\end{array}$ & 5 años \\
\hline Canarias $^{d}$ & Igual que la normativa estatal. & $99 \%$ & $\begin{array}{l}200.000 € \text { por el } \\
\text { valor conjunto de la } \\
\text { vivienda. }\end{array}$ & 5 años \\
\hline Cantabria $^{e}$ & $\begin{array}{l}\text { Para descendientes y adop- } \\
\text { tados, ascendientes y adop- } \\
\text { tantes, cónyuges, parejas de } \\
\text { hecho y tutores legales judi- } \\
\text { cialmente declarados del cau- } \\
\text { sante incapacitado. }\end{array}$ & $95 \%$ & $\begin{array}{c}125.000 € \text { por cada } \\
\text { sujeto pasivo. }\end{array}$ & 5 años \\
\hline \multicolumn{5}{|c|}{$\begin{array}{l}\text { b Arts. } 20 \text { y } 21 \text { del Decreto Legislativo } 1 / 2018 \text {, de } 19 \text { de junio, por el que se aprueba el Texto Refundido de las disposiciones } \\
\text { dictadas por la Comunidad Autónoma de Andalucía en materia de tributos cedidos. } \\
\text { c Art. } 131-8 \text { del Decreto Legislativo } 1 / 2015 \text {, de } 26 \text { de septiembre, del Gobierno de Aragón, por el que se aprueba el Texto } \\
\text { Refundido de las disposiciones dictadas por la Comunidad Autónoma de Aragón en materia de tributos cedidos. } \\
\text { d Art. } 22 \text {-ter del Decreto Legislativo } 1 / 2009 \text {, de } 21 \text { de abril, por el que se aprueba el Texto Refundido de las disposiciones } \\
\text { legales vigentes dictadas por la Comunidad Autónoma de Canarias en materia de tributos cedidos. } \\
\text { e Apartados } 1 \text { y } 5 \text { del art. } 5 \text { del Decreto Legislativo } 62 / 2008 \text {, de } 19 \text { de junio, por el que se aprueba el Texto Refundido de la } \\
\text { Ley de Medidas Fiscales en materia de Tributos cedidos por el Estado. }\end{array}$} \\
\hline
\end{tabular}




\begin{tabular}{|c|c|c|c|c|}
\hline $\begin{array}{l}\text { Castilla } \\
\text { y León }\end{array}$ & No se regula. & & & \\
\hline $\begin{array}{l}\text { Castilla- } \\
\text { La Mancha }\end{array}$ & No se regula. & & & \\
\hline Cataluña $^{h}$ & $\begin{array}{l}\text { También los miembros de } \\
\text { una relación de convivencia } \\
\text { de ayuda mutua, los } \\
\text { convivientes en pareja } \\
\text { estable y los hijos de su } \\
\text { cónyuge o del otro miembro } \\
\text { de la pareja estable. }\end{array}$ & $95 \%$ & $\begin{array}{l}180.000 € \text { por cada } \\
\text { sujeto pasivo y } \\
500.000 € \text { por } \\
\text { el valor conjunto } \\
\text { de la vivienda. }\end{array}$ & 5 años \\
\hline $\begin{array}{l}\text { Comunidad } \\
\text { de Madridi }\end{array}$ & $\begin{array}{l}\text { También los miembros de } \\
\text { uniones de hecho. }\end{array}$ & $95 \%$ & $\begin{array}{l}123.000 € \text { por cada } \\
\text { sujeto pasivo. }\end{array}$ & 5 años \\
\hline $\begin{array}{l}\text { Comunidad } \\
\text { Valenciana }\end{array}$ & $\begin{array}{l}\text { También los miembros de } \\
\text { parejas de hecho. }\end{array}$ & $95 \%$ & $\begin{array}{l}150.000 € \text { por cada } \\
\text { sujeto pasivo. }\end{array}$ & 5 años \\
\hline Extremadurak $^{k}$ & No se regula. & & & \\
\hline Galicia' & $\begin{array}{l}\text { También los miembros de } \\
\text { uniones estables de pareja. }\end{array}$ & $\begin{array}{l}\text { Del } 95 \% \\
\text { al } 99 \% \\
\text { en función } \\
\text { del valor real del } \\
\text { inmueble y del } 100 \% \\
\text { para el cónyuge. }\end{array}$ & $\begin{array}{l}600.000 € \text { por } \\
\text { el valor conjunto } \\
\text { de la vivienda. }\end{array}$ & 5 años \\
\hline $\begin{array}{l}\text { Islas } \\
\text { Baleares }^{m}\end{array}$ & $\begin{array}{l}\text { También los miembros de } \\
\text { parejas estables. }\end{array}$ & $100 \%$ & $\begin{array}{l}180.000 € \text { por cada } \\
\text { sujeto pasivo. }\end{array}$ & 5 años \\
\hline
\end{tabular}

\begin{tabular}{|c|c|c|c|c|}
\hline La Riojan & $\begin{array}{l}\text { Igual que la normativa } \\
\text { estatal. }\end{array}$ & $95 \%$ & $\begin{array}{l}122.606,47 € \text { para } \\
\text { cada sujeto pasivo. }\end{array}$ & 5 años \\
\hline $\begin{array}{l}\text { Principado } \\
\text { de Asturias }\end{array}$ & $\begin{array}{l}\text { También los miembros de } \\
\text { parejas de hecho y personas } \\
\text { que realicen o sean objeto de } \\
\text { un acogimiento familiar per- } \\
\text { manente o preadoptivo. }\end{array}$ & $\begin{array}{l}\text { Del } 95 \% \\
\text { al } 99 \% \\
\text { en función } \\
\text { del valor real del } \\
\text { inmueble. }\end{array}$ & $\begin{array}{c}122.606,47 € \text { por } \\
\text { cada sujeto pasivo. }\end{array}$ & 3 años \\
\hline
\end{tabular}

$\begin{array}{ll}\begin{array}{l}\text { Región } \\ \text { de Murcia }\end{array} & \text { No regulada. }\end{array}$

f Decreto Legislativo 1/2013, de 12 de septiembre, por el que se aprueba el Texto Refundido de las disposiciones legales de la Comunidad de Castilla y León en materia de tributos propios y cedidos.

9 Ley 8/2013, de 21 de noviembre, de Medidas Tributarias de Castilla-La Mancha.

h Arts. 17 a 19, 36, 59 y 60 de la Ley 19/2010, de 7 de junio, de regulación del Impuesto sobre Sucesiones y Donaciones.

Arts. 21.3 y 26 del Decreto Legislativo 1/2010, de 21 de octubre, del Consejo de Gobierno, por el que se aprueba el Texto Refundido de las disposiciones legales de la Comunidad de Madrid en materia de tributos cedidos por el Estado.

j Arts.10.Uno.c) y doce quater de la Ley 13/1997, de 23 de diciembre, de la Generalitat Valenciana, por la que se regula el tramo autonómico del impuesto sobre la renta de las personas físicas y restantes tributos cedidos.

k Decreto Legislativo 1/2018, de 10 de abril, por el que se aprueba el Texto Refundido de las disposiciones legales de la Comunidad Autónoma de Extremadura en materia de tributos cedidos por el Estado.

1 Arts. 7.Tres y 12 del Decreto Legislativo 1/2011, de 28 de julio, por el que se aprueba el Texto Refundido de las disposiciones legales de la Comunidad Autónoma de Galicia en materia de tributos cedidos por el Estado.

m Arts. 23 y 60 del Decreto Legislativo 1/2014, de 6 de junio, por el que se aprueba el Texto Refundido de las Disposiciones Legales de la Comunidad Autónoma de las Illes Balears en Materia de Tributos Cedidos por el Estado.

n Art. 35.4 de la Ley 10/2017, de 27 de octubre, por la que se consolidan las disposiciones legales de la Comunidad Autónoma de La Rioja, en materia de impuestos propios y tributos cedidos.

- Arts. 17.bis y 24 del Decreto Legislativo 2/2014, de 22 de octubre, por el que se aprueba el Texto Refundido de las disposiciones legales del Principado de Asturias en materia de tributos cedidos por el Estado.

p Decreto Legislativo 1/2010, de 5 de noviembre, por el que se aprueba el Texto Refundido de las Disposiciones Legales vigentes en la Región de Murcia en materia de Tributos Cedidos. 
REALA. Nueva Época - N.o 11, Abril-Septiembre 2019 - ISSN: 1989-8975 - DOI: 10.24965/reala.v0i11.10574 - [Págs. 122-138]

La reducción en el ISD por la adquisición de la vivienda habitual del causante: análisis estatal, autonómico y foral Irene Rovira Ferrer

\begin{tabular}{|c|c|c|c|c|}
\hline \multirow{2}{*}{$\frac{\text { Navarra }^{q}}{\text { Álava }^{r}}$} & \multicolumn{4}{|l|}{ No se regula. } \\
\hline & $\begin{array}{l}\text { El adquirente hubiese convivi- } \\
\text { do con el transmitente duran- } \\
\text { te los dos años anteriores a la } \\
\text { transmisión. }\end{array}$ & $95 \%$ & $212.242 €$ & No \\
\hline Guipúzcoas $^{\text {s }}$ & $\begin{array}{l}\text { El adquirente hubiese convivi- } \\
\text { do con el transmitente duran- } \\
\text { te los dos años anteriores a la } \\
\text { transmisión. }\end{array}$ & $95 \%$ & $220.000 €$ & No \\
\hline Vizcaya $^{t}$ & $\begin{array}{l}\text { El adquirente hubiese convivi- } \\
\text { do con el transmitente duran- } \\
\text { te los dos años anteriores a la } \\
\text { transmisión. }\end{array}$ & $95 \%$ & $215.000 €$ & No \\
\hline \multicolumn{5}{|c|}{$\begin{array}{l}\text { a Decreto Foral Legislativo de Navarra 250/2002, de } 16 \text { de diciembre, por el que se aprueba el Texto Refundido de las dispo- } \\
\text { siciones del Impuesto sobre Sucesiones y Donaciones. } \\
\text { r Art. } 22.8 \text { de la Norma Foral de Álava } 11 / 2005 \text {, de } 16 \text { de mayo, del Impuesto sobre Sucesiones y Donaciones. } \\
\text { s Art. } 19.1 \text { de la Norma Foral 3/1990, de } 11 \text { de enero, del Impuesto sobre Sucesiones y Donaciones del Territorio Histórico } \\
\text { de Guipúzcoa. } \\
\text { t Art. } 44 \text { de la Norma foral de Vizcaya 4/2015, de } 25 \text { de marzo, del Impuesto sobre Sucesiones y Donaciones. }\end{array}$} \\
\hline
\end{tabular}

Fuente: Elaboración propia.

\section{EL CONCEPTO DE VIVIENDA HABITUAL DEL CAUSANTE}

Por lo que respecta a la LISD, no define el concepto de vivienda habitual a efectos de la reducción del art. 20.2.c), aunque sí que lo hizo el epígrafe 1.4.b) de la Resolución 2/1999. Así, señaló expresamente que, «para la determinación de lo que ha de entenderse por vivienda habitual, hay que acudir al artículo 51 del Reglamento del Impuesto sobre la Renta de las Personas Físicas, aprobado por el Real Decreto 214/1999, de 5 de febrero [actual art. 41.bis del Real Decreto 439/2007, de 30 de marzo, por el que se aprueba el Reglamento del Impuesto sobre la Renta de las Personas Físicas y se modifica el Reglamento de Planes y Fondos de Pensiones (RIRPF), aprobado por Real Decreto 304/2004, de 20 de febrero], que es el que define dicho concepto en el ámbito fiscal».

$Y$ al respecto, señala el primer apartado del mencionado precepto que se considerará vivienda habitual del contribuyente «la edificación que constituya su residencia durante un plazo continuado de, al menos, tres años», aunque, como añade, "se entenderá que la vivienda tuvo el carácter de habitual cuando, a pesar de no haber transcurrido dicho período, se produzca el fallecimiento del contribuyente o concurran otras circunstancias que necesariamente exijan el cambio de domicilio, tales como celebración de matrimonio, separación matrimonial, traslado laboral, obtención del primer empleo, o cambio de empleo, u otras análogas justificadas».

De este modo, como ha puntualizado la DGT, la excepción que se contempla en el RIRPF, relativa a las causas justificadas del traslado, se predica exclusivamente respecto a la exigencia del plazo de tres años para que una vivienda pueda tener la consideración de habitual, de modo que «implica únicamente que se consolidan las deducciones anteriormente practicadas o que, si la vivienda se transmitiese en dicho momento, se podría aplicar el beneficio fiscal de la exención por reinversión en otra vivienda habitual o por transmisión por personas mayores de 65 años». Sin embargo, como añade expresamente, «una vez transcurridos los tres años de residencia, la vivienda sólo tendrá el carácter de habitual mientras en ella mantenga su residencia el propietario, perdiendo ese carácter a partir del momento en que deje de residir en la misma, cualquiera que sea su causa» ${ }^{5}$.

No obstante, y aunque el art. 41.bis del RIRPF y la posición de la DGT sean claros, el TS ha establecido otro criterio en unificación de doctrina mediante la STS 841/2017, de 12 de mayo, concretamente al enjuiciar

\footnotetext{
5 Resolución de la Consulta Vinculante de la DGT V1930-07, de 14 de septiembre, la cual entendió justamente que la que había sido la vivienda habitual de la causante hasta que tuvo que ser trasladada al domicilio de uno de sus hijos por razones graves de salud (donde residió los últimos siete años) había perdido tal carácter a efectos de la reducción del art. 20.2.c) de la LISD. En la misma línea, pueden verse otras resoluciones a consultas de la DGT como la V0132-04, de 24 de septiembre, o la 0672-03, de 20 de mayo.
} 
un supuesto en el que la causante, debido a su estado de salud, había dejado de residir en su vivienda habitual para trasladarse a la vivienda de su hermano más de tres años antes de su fallecimiento.

Así, el TS se ha acogido a las "otras causas análogas justificadas» del traslado que contempla el art. 41.bis del RIRPF para entender que la que era la vivienda habitual de la causante antes de mudarse al domicilio de su hermano no perdió dicho carácter a pesar de que dejara de residir en la misma, alegando que, dentro de las causas mencionadas, «ha de incluirse la enfermedad acreditada que obliga al cambio de residencia, máxime cuando el fallecimiento sobreviene durante y como consecuencia de dicha enfermedad».

Sin embargo, como se ha señalado, la excepción que contempla el RIRPF se predica únicamente respecto a la exigencia de que una persona residida un mínimo de tres años en el pertinente inmueble para que éste pueda tener la consideración de vivienda habitual, de modo que, una vez haya pasado dicho período necesario para que goce de tal condición, el inmueble dejará de ser la vivienda habitual del contribuyente desde el momento en el que deje de residir en el mismo, con total independencia de cuál sea su causa.

De hecho, además de la DGT, así ha sido considerado también por otros tribunales, los cuales, a diferencia del TS, no han reconocido el derecho de aplicar la reducción del art. 20.2.c) de la LISD por la transmisión de la que en su momento había constituido la vivienda habitual del causante, al entender que, desde que el causante dejó de residir en la misma, el inmueble perdió tal condición ${ }^{6}$.

$Y$ es que, si bien el apartado 3 del mismo art. 41.bis mantiene la condición de vivienda habitual del contribuyente a aquella que lo fue «hasta cualquier día de los dos años anteriores a la fecha de transmisión», la limita específicamente tal consideración «a los exclusivos efectos» de la aplicación de las exenciones previstas en los artículos 33.4. b) y 38 de la Ley $35 / 2006$, de 28 de noviembre, del Impuesto sobre la Renta de las Personas Físicas y de modificación parcial de las leyes de los Impuestos sobre Sociedades, sobre la Renta de no Residentes y sobre el Patrimonio (LIRPF), las cuales son relativas, respectivamente, a la exención de las ganancias patrimoniales que se pongan de manifiesto con ocasión de la transmisión de su vivienda habitual por mayores de 65 años o por personas en situación de dependencia severa o de gran dependencia (conforme a la Ley de promoción de la autonomía personal y atención a las personas en situación de dependencia), y a la exención de las ganancias patrimoniales obtenidas por la transmisión de la vivienda habitual del contribuyente, siempre que el importe total obtenido por la transmisión se reinvierta en la adquisición de una nueva vivienda habitual.

Por consiguiente, en los términos actualmente vigentes, resulta claro que la normativa no contempla la reducción del art. 20.2.c) de la LISD cuando el causante hubiera dejado de residir en su vivienda habitual (a considerar que habrá perdido tal carácter), y no hay que olvidar en este punto que tanto el TS como la Administración tributaria, en tanto que órganos públicos, se encuentran plenamente sometidos al estricto cumplimiento de la misma.

No obstante, cuestión distinta es que la mencionada reducción sí que pueda aplicarse en tales supuestos si resulta de aplicación una normativa autonómica que así lo prevea de forma expresa (mejorando, de este modo, la reducción estatal), lo que ciertamente ha tenido lugar en tres CCAA aunque de forma diferente.

Así, en primer lugar, procede destacar las previsiones de Canarias al respecto, donde se señala que, si el causante hubiera tenido su último domicilio en un centro residencial o socio-sanitario, la reducción aquí estudiada podrá aplicarse sobre aquella vivienda en la que efectivamente hubiera tenido su residencia habitual inmediatamente antes de su cambio de domicilio al citado centro ${ }^{7}$. En la misma línea, Galicia apunta que se entenderá que la última vivienda habitual en la que residió el causante no ha perdido tal carácter cuando, por circunstancias físicas o psíquicas, se hubiera trasladado a un centro especializado para recibir cuidados, aunque en este caso se añade que tampoco perderá tal condición cuando, por las mismas circunstancias, se hubiera trasladado a vivir con los familiares incluidos en el grupo de parentesco que da derecho a obtener la reducción del art. 20.2.c) de la LISD ${ }^{8}$.

$Y$ en un sentido similar, también Cataluña ha adoptado su normativa en tales términos pero añadiendo una limitación temporal, por cuanto señala que, si el causante, en la fecha de su muerte, tenía su residencia

\footnotetext{
6 Entre otras, respecto al mismo supuesto aquí planteado, véase la STSJ de Canarias 308/2015, de 23 de octubre de 2015, del mismo modo que puede verse la STSJ de Castilla y León 330/2013, de 23 de julio de 2013, al señalar que el traslado definitivo y permanente del causante a una residencia geriátrica hizo perder, «conforme a la normativa y jurisprudencia citada, el carácter de vivienda habitual a aquella en donde se ha venido residiendo hasta dicho momento».

7 Art. 22-ter.3 del Decreto Legislativo 1/2009, de 21 de abril, por el que se aprueba el Texto Refundido de las disposiciones legales vigentes dictadas por la Comunidad Autónoma de Canarias en materia de tributos cedidos.

8 Art. 7.Tres. 1 del Decreto Legislativo 1/2011, de 28 de julio, por el que se aprueba el Texto Refundido de las disposiciones legales de la Comunidad Autónoma de Galicia en materia de tributos cedidos por el Estado.
} 
efectiva en un domicilio del que no era titular, tendrá la consideración de vivienda habitual la que tenía esta condición hasta cualquier día de los diez años anteriores a la fecha de la muerte pero, curiosamente, si hubiera tenido su último domicilio en un centro residencial o socio-sanitario, no se aplicará ningún límite temporal ${ }^{9}$.

No obstante, procede resaltar en este punto la cuestionable discriminación que pueden conllevar tanto la normativa canaria como la catalana respecto a aquellos familiares que, por los mismos motivos que podrían requerir el ingreso del causante en una residencia o centro socio-sanitario, se hubieran hecho cargo del mismo trasladándolo a su domicilio (en el caso catalán, si el cambio de residencia se hubiera producido más de diez años antes de su fallecimiento), especialmente respecto a los sujetos que no sean parientes colaterales (ya que, como se ha señalado, no se les exige el requisito de convivencia para poder tener derecho a la reducción).

$Y$ es que puede darse el caso de que familiares directos que no se hubieran hecho cargo del causante ni residan en la que fue su vivienda habitual puedan aplicarse la reducción mientras que se niegue otros que tuvieron cura del mismo trasladándolo a su propio domicilio, lo cual, aparte de resultar contrario a los principios de igualdad tributaria (que requiere la equidad real en la distribución de la carga tributaria) ${ }^{10}$ y generalidad (que prohíbe cualquier tipo de discriminación o privilegio en el reparto de la carga tributaria que no se encuentre debidamente justificado) ${ }^{11}$, podría vulnerar el principio de igualdad ante la Ley que contempla el art. 14 de la CE.

Así, respecto al triple examen que el TC ha fijado para determinar su vulneración, se trata de situaciones objetivamente comparables (ya que en ambos casos se trata de familiares directos y de un causante que no residía en la que fue su vivienda habitual por razones de salud), pero no existe un fin objetivo, razonable y constitucionalmente válido que legitime su trato diferenciado ( $y$ más considerando que los sujetos a los que se les niega la reducción se hacían cargo del mismo en su propio domicilio), siendo las consecuencias jurídicas derivadas de esta distinción del todo injustificadas y desproporcionadas (atendiendo especialmente a la cuantía a la que puede ascender la reducción) ${ }^{12}$.

Por consiguiente, y teniendo en cuenta que los fines que justifican este beneficio fiscal son tanto la protección del deber de protección a la familia como del derecho a una vivienda digna y adecuada, parece que en ningún caso deberían tenerse en cuenta los traslados permanentes de carácter forzoso del causante, como podrían ser los producidos por motivos de salud o los derivados incluso de su separación o divorcio (evitando de este modo la discriminación que, por ejemplo, podrían soportar los descendientes que, por residir con el otro progenitor en la que había sido la vivienda habitual del causante, quedaran fuera de la reducción).

Pero, además, para su óptima procedencia, parece que tampoco deberían considerarse aquellos cambios de residencia temporales por motivos justificados (como pueden de trabajo o de estudios), salvedades que en ambos casos deberían preverse por la propia LISD y sin vincularse a ninguna limitación temporal.

Por último, procede determinar también qué concretos elementos conforman el concepto de vivienda habitual, lo cual, respecto a la regulación estatal, ha venido precisado por la DGT en la Resolución a la Consulta Vinculante V3752-15, de 26 de noviembre. Así, como ha señalado, una vez «examinada la reducción establecida en el artículo 20.2.c) de la Ley 29/1987 desde la realidad social en que ha de ser aplicada, ha de permitirse una ampliación del concepto estricto de vivienda a aquellos elementos (caso del garaje) vinculados con la misma, ya se entienda dicha vinculación desde el punto de vista de su configuración registral o desde el punto de vista de su consideración unitaria en el tráfico jurídico». Por consiguiente, añade, «habrá vinculación cuando el garaje constituya una finca registral única junto con la vivienda o, cuando, tratándose de distintas fincas registrales, se configure como anejo inseparable de la misma desde el punto de vista de

\footnotetext{
9 Art. 18.3 de la Ley 19/2010, de 7 de junio, de regulación del Impuesto sobre Sucesiones y Donaciones.

10 Al respecto, y aunque el TC ha reiterado en sentencias como la STC 3/1983, de 25 de enero, que cabe y debe adoptarse «todo mandato de desigualdad o diferenciación que logre precisamente la igualdad real» (permitiéndose así «regulaciones cuya desigualdad formal se justifica en la promoción de la igualdad material, para reequilibrar la desigualdad originaria de las condiciones económicas, sociales o de posición jurídica de las personas»), no es lo que ocurre en este caso, ya que se da un trato fiscal más perjudicial a quienes justamente se hacían cargo del causante en su propio domicilio.

11 En concreto, así lo manifiestan MARTíN QUERALT, LOZANO SERRANO, CASADO OLLERO Y TEJERIZO LÓPEZ (2000), pág. 108, quienes señalan que el principio constitucional de generalidad «constituye un requerimiento directamente dirigido al legislador para que cumpla con una exigencia: tipificar como hecho imponible todo acto, hecho o negocio jurídico que sea indicativo de capacidad económica (...) vedando la concesión de exenciones y bonificaciones tributarias que puedan reputarse como discriminatorias».

12 Entre otras, véase la consolidada doctrina del TC respecto a este triple examen a la hora de considerar vulnerado el principio de igualdad en las SSTC 46/1999, de 22 de marzo; 200/2001, de 4 de octubre; 39/2002, de 14 de febrero; o 96/2002, de 25 de abril.
} 
su consideración unitaria en el tráfico jurídico. La vinculación debe resultar de forma indubitada de las circunstancias concurrentes en su adquisición, ya sea por su ubicación en el mismo inmueble, por su adquisición en el mismo acto (aunque sea en distinto documento) o, desde un punto de vista finalista, por adquirirse dichos bienes para ser arrendados conjuntamente con la vivienda».

Sin embargo, algunas autonomías también han ampliado el concepto de vivienda habitual en este punto, añadiendo como parte de la misma determinados elementos. Así, Cantabria señala que podrán considerarse como vivienda habitual, conjuntamente con la vivienda, un trastero y hasta dos plazas de aparcamiento, pese a no haber sido adquiridos simultáneamente en unidad de acto, si están ubicados en el mismo edificio o complejo urbanístico y si en la fecha de la muerte del causante se hallaban a su disposición, sin haberse cedido a terceros ${ }^{13}$, lo mismo que contempla Cataluña (aunque señalando que la prohibición de cesión que no operará si el causante, en el momento de su muerte, tenía su residencia efectiva en un domicilio del que no era titular) ${ }^{14}$ y Canarias (si bien haciendo referencia a una sola plaza de aparcamiento) ${ }^{15}$.

No obstante, es importante destacar finalmente la precisión que realiza esta última autonomía al establecer que, «para la aplicación de la reducción establecida en el presente artículo, la vivienda habitual ha de estar radicada en Canarias ${ }^{16}$, limitación que, además de inconstitucional, puede comportar una discriminación contraria al Derecho europeo.

Y es que puede darse el caso que resulte aplicable la normativa autonómica pero la vivienda habitual del causante esté radicara fuera de dicha CCAA, como ocurriría si el causante hubiera permanecido el mayor número de días de los cinco años inmediatos anteriores a su fallecimiento en un centro residencial o socio-sanitario ubicado en la Comunidad canaria (lo que, conforme al art. 32 de la Ley 22/2009, comportaría la aplicación de la normativa autonómica del ISD), pero la vivienda en la que efectivamente hubiera tenido su residencia habitual inmediatamente antes de su cambio de domicilio al citado centro estuviera radicada fuera de su territorio.

De este modo, el único motivo que justificaría el no reconocimiento del beneficio fiscal en tales casos sería la no ubicación de la vivienda en el territorio canario, lo cual, como señaló la STC 60/2015, de 18 de marzo, no es un elemento válido de diferenciación en situaciones objetivamente comparables por cuanto no puede justificar discriminación alguna. En consecuencia, como añadió, no sólo se vulnera en tales casos el principio de igualdad que contempla el art. 14 de la CE, sino también el principio de igualdad tributaria junto con el deber general de contribuir previstos en el art. 31.1 de la $\mathrm{CE}^{17}$.

Además, no hay que olvidar que también el Tribunal de Justicia de la Unión Europea (TJUE) ha señalado la improcedencia de las diferencias de trato en la tributación de las adquisiciones lucrativas justificadas únicamente en la territorialidad nacional, es decir, que sólo por el hecho de existir un elemento fuera del territorio de un Estado se aplique un trato fiscal menos beneficioso a la correspondiente sucesión o donación (lo que ha considerado contrario a las obligaciones previstas en el art. 63 del Tratado de Funcionamiento de la Unión Europea -TFUE- y 40 del Acuerdo sobre el Espacio Económico Europeo -AEEE-).

De hecho, en el caso de España, así lo entendió justamente en relación con los puntos de conexión previstos por Ley 22/2009, al apuntar que, conforme a los mismos, resultaba de aplicación la normativa estatal y no la autonómica (fiscalmente más beneficiosa) por criterios basados únicamente en la territorialidad nacional. De este modo, como señaló la STJUE de 3 de septiembre de 2014 (asunto C-127/12), la Ley 22/2009 incumplía los mencionados preceptos al permitir que se establecieran «diferencias [injustificadas y, por ende, discriminatorias] en el trato fiscal de las donaciones y las sucesiones entre los causahabientes y los donatarios residentes y no residentes en España, entre los causantes residentes y no residentes en España y entre las donaciones y las disposiciones similares de bienes inmuebles situados en territorio español y fuera de éste».

13 Art. 5.4 del Decreto Legislativo 62/08, de 19 de junio, por el que se aprueba el Texto Refundido de la Ley de Medidas Fiscales en materia de Tributos cedidos por el Estado.

${ }_{14}$ Art. 18.1 de la Ley 19/2010, de 7 de junio, de regulación del Impuesto sobre Sucesiones y Donaciones.

15 Art. 22-ter.2 del Decreto Legislativo 1/2009, de 21 de abril, por el que se aprueba el Texto Refundido de las disposiciones legales vigentes dictadas por la Comunidad Autónoma de Canarias en materia de tributos cedidos.

${ }_{16}$ Art. 22-ter.4 del Decreto Legislativo 1/2009, de 21 de abril, por el que se aprueba el Texto Refundido de las disposiciones legales vigentes dictadas por la Comunidad Autónoma de Canarias en materia de tributos cedidos.

17 En concreto, la mencionada sentencia declaró la inconstitucionalidad del art. 12.bis.a) de la Ley 13/1997 de la Comunidad Valenciana (concretamente, en la redacción dada por el art. 16 de la Ley 10/2006, de 26 de diciembre, de la Comunidad Valenciana), donde se contemplaba una bonificación del $99 \%$ de la cuota del ISD en las adquisiciones mortis causa entre parientes de los Grupos I y II pero siempre que los sucesores tuvieran su residencia habitual en dicha autonomía. 
Y por lo que aquí respecta es importante destacar que tales diferencias no se predicaban únicamente respecto a los contribuyentes que no fueran residentes en España, sino que también se constataron tales discriminaciones cuando el causante no fuera residente pero sí el sucesor, así como en el caso de donaciones de inmuebles radicados fuera del territorio español (ya que en tales casos el sujeto pasivo debe ser necesariamente residente, puesto que los no residentes sólo tributan por obligación real, limitada a los bienes y derechos en España -art. 7 de la LISD-).

Así pues, respecto a este último supuesto, también dejó clara la discriminación injustificada que supone el limitar la procedencia de un trato fiscal más beneficioso a un concreto territorio en el que se debe encontrar el bien objeto de adquisición, y es que, sin ir más lejos, el art. 40 del AEEE prohíbe las discriminaciones de trato por razón «del lugar donde se hayan invertido los capitales».

\section{LOS SUJETOS QUE TIENEN DERECHO A LA REDUCCIÓN}

Aunque el Real Decreto-Ley 7/1996, de 7 de junio, justificó la incorporación de la reducción aquí estudiada alegando que pretendía «aliviar el coste fiscal derivado de la transmisión mortis causa (...) de la vivienda habitual, cuando dicha transmisión se efectuase en favor de ciertas personas allegadas al fallecido», el art. 20.2.c) de la LISD señala que únicamente tendrán derecho a la misma el cónyuge, los ascendientes o los descendientes del causante, así como los colaterales mayores de 65 años que hubieran convivido con el mismo durante los dos años anteriores al fallecimiento.

Por consiguiente, con base en tales consideraciones, resalta, en primer lugar, la distinción que realiza la LISD respecto al requisito de convivencia a la hora de determinar los sujetos que tendrán derecho a la misma, lo que viene a desvirtuar los dos motivos principales que fundamentan su procedencia.

Así, por lo que respecta al derecho a disfrutar de una vivienda digna y adecuada (contemplado en el art. 47 de la CE), sorprende inicialmente que, a diferencia de lo que ocurre en los territorios históricos forales del País Vasco, no se exija que los familiares directos que tengan derecho a la reducción tuvieran en el pertinente inmueble su vivienda habitual (ya que es evidente que, para aquellos que no la tuvieran, no puede justificarse su trato diferencial con base en el mencionado derecho constitucional), del mismo modo que resulta difícilmente justificable que, a diferencia de lo que también ocurre en los mencionados territorios históricos, no se reconozca a aquellas personas que convivieran con causante siendo colaterales menores de 65 años o sin que tuvieran un vínculo de parentesco con él (por cuanto que en este caso sí que el mencionado derecho debería gozar de la tutela necesaria y más considerando que tampoco gozarán de los demás beneficios fiscales que se contemplan para los familiares directos ni de las facilidades de aplazamiento y fraccionamiento de la cuota tributaria que se prevén en tales supuestos).

Y por su parte, en relación con la protección social, económica y jurídica de la familia que requiere el art. 39 de la CE, resalta asimismo la discriminación que supone para aquellos familiares directos respecto a los que no se transmita una vivienda habitual, ya que se atenta claramente contra el principio de generalidad al discriminar la adquisición de otras formas de riqueza. Además, al no exigirse que el inmueble adquirido pase a ser la vivienda habitual del adquirente, éste podrá beneficiarse de la pertinente reducción por tantas viviendas habituales como adquiera, lo cual, junto al requisito de permanencia en su patrimonio, influye claramente en las decisiones de los ciudadanos con las rentas más elevadas (vulnerando claramente el principio de neutralidad fiscal) ${ }^{18}$.

Además, y aunque dentro de los sujetos con derecho a la reducción deban entenderse incluidos los adoptantes y los adoptados ${ }^{19}$, procede realizar algunas precisiones sobre los mismos, lamentando la exclusión de algunas personas que, por encontrarse en las mismas condiciones que los sujetos expresamente previstos por el art. 20.2.c) de la LISD, también deberían entenderse incluidas con base en el principio de igualdad y el de igualdad tributaria (arts. 14 y 31 de la CE).

${ }^{18}$ En la misma línea, véase GARCÍA DE PABLOS (2001), pág. 86, donde se señala que «la actual regulación puede infringir el principio de neutralidad impositiva, al influir en las decisiones de los particulares sobre sus inversiones».

${ }_{19}$ Al respecto, el epígrafe 1.4.a) de la Resolución 2/1999 señala que, «dado que la Ley cita a los ascendientes en descendientes en términos generales, debe aplicarse la reducción también en los casos de adquisición "mortis causa" de la vivienda habitual del causante por los adoptantes y adoptados, sobre todo teniendo en cuenta que el artículo 108 del Código Civil dispone que la filiación matrimonial y la no matrimonial, así como la adoptiva plena surten los mismos efectos conforme a las disposiciones del Código». 
Así, en primer lugar, debe realizarse una especial referencia a los descendientes, ascendientes y colaterales por afinidad, donde, respecto a los primeros, la DGT había establecido que, en tanto que «la afinidad es un vínculo que surge como consecuencia del matrimonio entre uno de los cónyuges y los consanguíneos del otro», «si ese vínculo subsistía en el momento del fallecimiento del causante, el descendiente por afinidad tendría derecho a la reducción del artículo 20.2.c) [LISD]» ${ }^{20}$.

Sin embargo, como recogió la STS 1086/2017, de 24 de marzo, dictada en casación para la unificación de doctrina, la extinción del vínculo matrimonial del que surge el parentesco por afinidad no supone, a los efectos del ISD, que el pariente afín se convierta en un extraño, sino que debe seguirle siendo aplicable la reducción derivada de su grado de afinidad prevista en la normativa del tributo ${ }^{21}$. Por consiguiente, a pesar de que el vínculo matrimonial del que derivaba su parentesco se hubiera extinguido (ya sea por divorcio o fallecimiento), parece que todos los parientes afines podrán tener derecho a la reducción prevista en el art. 20.2.c) de la LISD, y es que, aunque la normativa estatal no se refiera explícitamente a los colaterales afines (ya que simplemente menciona a los "colaterales»), deben entenderse incluidos igual que los consanguíneos (siendo procedente su reducción si hubieran convivido con el causante durante los dos últimos años anteriores a su fallecimiento) ${ }^{22}$.

De este modo, es importante destacar la improcedencia de la normativa gallega al limitar el reconocimiento de la reducción aquí estudiada a los parientes colaterales por consanguinidad ${ }^{23}$, sin olvidar que las competencias normativas de las CCAA de régimen común respecto a las reducciones a la base imponible del ISD previstas por el Estado quedan limitadas a su mejora.

Por su parte, y a pesar de la conveniencia de su inclusión, los que no pueden considerarse sujetos con derecho a la reducción son aquellas personas que hayan realizado o hayan sido objeto de un acogimiento familiar permanente o preadoptivo, ya que el art. 108 del Código Civil únicamente equipara los efectos de la filiación matrimonial, la no matrimonial y la adoptiva. En consecuencia, y aunque las razones que justificarían la protección de la familia operarían también en tales casos (motivo por el cual no sólo se reconoce a dichos sujetos el derecho a la aplicación del mínimo por descendientes en el IRPF ${ }^{24}$ sino que incluso pueden presentar una declaración conjunta al considerarse unidad familiar ${ }^{25}$ ), no se encuentran expresamente contemplados por la norma estatal y, por consiguiente, no tendrán derecho a la mencionada reducción, motivo por el cual procede aplaudir la iniciativa operada por las CCAA de Andalucía y el Principado de Asturias que, como se ha visto, han ampliado la reducción del Estado reconociéndosela en sus territorios.

Asimismo, por idénticas razones también resulta acertado el reconocimiento de la reducción a los tutores legales judicialmente declarados de los causantes que hubieran sido incapacitados que, con independencia de su parentesco, ha hecho Cantabria (especialmente si compartían la vivienda habitual), así como la que han realizado Andalucía, Cantabria, Cataluña, la Comunidad de Madrid, la Comunidad Valenciana, Galicia, las Islas Baleares y el Principado de Asturias a las denominadas uniones estables de pareja o parejas de hecho.

Y es que en este punto procede resaltar las consideraciones de la STS 812/2002, de 8 de febrero al respecto (donde se valoró justamente si los beneficios fiscales previstos para los cónyuges en el ISD resultaban

20 Resolución a la Consulta vinculante de la DGT V1375-10, de 18 de junio de 2010.

21 En este punto, citando la STS 3405/2017, de 25 de septiembre, resulta interesante reproducir el párrafo con el que cierra su posicionamiento al respecto, al apuntar que «en nuestro sistema sucesorio el pariente afín solo puede ser llamado a la herencia por testamento al no estar prevista -como se sigue de nuestro Código Civil- su sucesión abintestato. Quiere ello decir, por tanto, que la voluntad del causante es instituir heredero o nombrar legatario a su pariente político a pesar de la extinción anterior -por muerte de su cónyuge, pariente consanguíneo del llamado- del vínculo matrimonial que originó la afinidad. Si ello ha sido así es, sin duda, porque el vínculo afectivo se mantiene no obstante aquella extinción, lo que no puede ser desconocido -a nuestro juicio- por las normas tributarias que gravan la sucesión».

${ }^{22}$ Al respecto, la STS 1847/2003, de 18 de marzo, tras considerar que «donde la Ley no distingue no cabe distinguir», señaló que es obvio que «el legislador no ha querido que existieran diferencias entre los colaterales por consanguinidad y por afinidad, derogando las normas contrarias que han estado vigentes, reglamentariamente, hasta 1967» (todas ellas relativas al ISD). Y en el mismo sentido, véase la STS 1842/2017, de 28 de noviembre, dictada también en unificación de doctrina, en la que, además de reiterar que la relación de afinidad se mantiene aún después de la disolución del vínculo matrimonial que originó dicha relación, añade que los cuñados y tíos y sobrinos políticos deben tributar por el ISD como los hermanos y tíos y sobrinos consanguíneos (por cuanto es únicamente respecto a los descendientes que la LISD les establece un trato diferenciado en función de su vínculo por afinidad o consanguinidad -art. 20.2.a) de la LISD-).

${ }^{23}$ Art. 7.Tres.1 del Decreto Legislativo 1/2011, de 28 de julio, por el que se aprueba el Texto Refundido de las disposiciones legales de la Comunidad Autónoma de Galicia en materia de tributos cedidos por el Estado.

${ }^{24}$ Art. 58 de la Ley 35/2006, de 28 de noviembre, del Impuesto sobre la Renta de las Personas Físicas y de modificación parcial de las leyes de los Impuestos sobre Sociedades, sobre la Renta de no Residentes y sobre el Patrimonio.

${ }^{25}$ Véase al respecto la Resolución a la Consulta Vinculante de la DGT V1845-17, de 12 de julio de 2017. 
REALA. Nueva Época - N.o 11, Abril-Septiembre 2019 - ISSN: 1989-8975 - DOI: 10.24965/reala.v0i11.10574 - [Págs. 122-138]

La reducción en el ISD por la adquisición de la vivienda habitual del causante: análisis estatal, autonómico y foral

Irene Rovira Ferrer

aplicables a los convivientes more uxorio -especialmente por lo que respectaba al menor gravamen de su tarifa- o si se les debían aplicar las previsiones relativas a los parientes colaterales a partir del cuarto grado y personas que no tuvieran parentesco con el testador), puesto que el TS fue rotundo al considerar que, aun participando de la sensibilidad social que llevaría a asimilar las uniones de hecho con los matrimonios, él y, en tanto que órgano público, la Administración tributaria se encuentran obligados al estricto cumplimiento de la ley. En consecuencia, y a pesar de que la interpretación de las normas debe realizarse con criterios no sólo históricos, lógicos y sistemáticos sino también sociopolíticos, si la normativa del ISD únicamente hace referencia a los cónyuges, sólo a quienes se hallen unidos por matrimonio les resultará de aplicación (tanto por la aplicación de los arts. 66, 67 y 68 del Código Civil como por el mismo significado que le da a dicho término la Real Academia Española de la Lengua), ya que tampoco procederían en este caso las tres condiciones exigidas por su doctrina a la hora de permitir la aplicación analógica de tales previsiones.

En este sentido, en opinión del TS, no existe, en primer lugar, una laguna legal que permita su aplicación (en el sentido de que la tributación de los miembros de las parejas de hecho puede deducirse según la letra y el sentido lógico de las normas existentes), del mismo modo que, en segundo lugar, entendió que no concurría una igualdad jurídica esencial entre el supuesto no regulado y el previsto por la ley, en tanto que los miembros de las uniones estables de pareja son libres de casarse y asumir, en consecuencia, las cargas, obligaciones, ventajas y beneficios del matrimonio (añadiendo que, si los miembros de una unión estable de pareja no se casan y, por consiguiente, quedan libres de tales cargas y obligaciones, tampoco pueden disfrutar las ventajas o beneficios previstos al respecto).

No obstante, procede remarcar que, hoy en día, tales consideraciones pierden su fuerza en tanto que la constitución de esta institución ya se encuentra jurídicamente formalizada y se ha regulado, con una serie de cargas y obligaciones, a nivel autonómico (ya que, aparte del Derecho foral, y a diferencia de lo que contempla el art. 149.1.8 de la CE en relación con los matrimonios, el texto constitucional no reserva al Estado competencias exclusivas al respecto), si bien es cierto que, en tercer lugar, el art. 14 de la LGT no permite acudir a la analogía para extender más allá de sus términos estrictos el ámbito del hecho imponible y de las exenciones y demás beneficios o incentivos fiscales.

De todos modos, considerando que la extensión de la reducción aquí estudiada a las parejas de hecho no se encuentra justificada desde la óptica de la analogía sino desde los propios principios de justicia tributaria (esencialmente, por el de igualdad tributaria ${ }^{26}$ ), es de suma relevancia que, igual que respecto al resto de sujetos excluidos, se incluya sin mayor demora en la LISD, reconocimiento que, como ha resaltado la DGT, deberá realizarse de forma expresa ${ }^{27}$.

Por su parte, y en relación directa con esta institución, procede asimismo destacar la aclaración que ha hecho Cataluña a la hora de especificar que también los hijos del cónyuge del causante o del otro miembro de la pareja estable tendrán derecho a la reducción aquí estudiada, aunque, como se ha señalado, en el caso de los cónyuges, así se desprende también de la regulación estatal (con base en los razonamientos realizados en torno a la filiación por afinidad). En consecuencia, en aquellas autonomías donde se haya equiparado la pareja de hecho al matrimonio respecto a las previsiones del ISD, también parece que los mismos razonamientos resultarán aplicables, aunque no esté de más su previsión concreta considerando que es el Código Civil el que sujeta la afinidad al vínculo matrimonial.

Finalmente, procede hacer también una especial mención del acierto de la normativa catalana al incluir como sujetos con derecho a la estudiada reducción a los miembros de una relación de convivencia de ayuda mutua que hubieran convivido el causante los dos años antes de su muerte, equiparándolos, de hecho, a los descendientes de veintiún años o más, al cónyuge y a los ascendientes también al efecto de la aplicación de las reducciones por circunstancias personales y del coeficiente multiplicador para la determinación de la cuota tributaria.

En concreto, las relaciones convivenciales de ayuda mutua se encuentran reguladas en los arts. 240-1 a 240-7 de la Ley 25/2010, de 29 de julio, del libro segundo del Código Civil de Cataluña, relativo a la persona

${ }^{26} \mathrm{Al}$ respecto, contenido en el art. 31 de la CE, el principio de igualdad tributaria requiere que todas las situaciones económicas equivalentes sean tratadas de la misma manera y que se vele por conseguir la equidad real en la distribución de la carga tributaria, por lo que es difícilmente aceptable que la reducción que aquí el legislador ha considerado pertinente conceder a los matrimonios no sean reconocida a las parejas de hecho que conviven en las idénticas condiciones.

${ }_{27}$ En este punto, como resaltó la Resolución de la Consulta Vinculante de la DGT de 10 de marzo de 2016, incluso en el caso de que se encontrara expresamente prevista la equiparación de los derechos civiles entre los matrimonios y las uniones estables de pareja (como ocurre, por ejemplo, en la CCAA gallega -Disposición adicional tercera de la Ley 2/2006, de 14 de junio, de Derecho Civil de Galicia-), «nunca se pueden extrapolar dichos derechos a efectos tributarios». 
y la familia, donde se definen como aquellas en que dos o más personas (hasta 4 si no son parientes) conviven en una misma vivienda habitual y que comparten, sin contraprestación y con voluntad de permanencia y de ayuda mutua, los gastos comunes o el trabajo doméstico, o ambas cosas (rigiendo preferentemente los acuerdos que hayan estipulado). Su constitución puede realizarse en escritura pública, a partir de la cual tienen plena efectividad, o por el transcurso de dos años de convivencia, pudiendo constituirlas las personas mayores de edad unidas por vínculos de parentesco en línea colateral sin límite de grado y las que tienen relaciones de simple amistad o compañerismo (siempre y cuando no estén unidas por un vínculo matrimonial o formen una pareja estable con otra persona con la que convivan).

Así pues, resulta sumamente adecuada la inclusión de esta particular institución por cuanto permite realmente la garantía del derecho de acceso a la vivienda mediante la mencionada reducción a las personas que realmente convivieran con el causante con independencia de su parentesco, aunque, sin lugar a dudas, lo más adecuado sería que, con carácter general, se adoptara la posición por la que han optado los territorios históricos forales del País Vasco al reconocer la reducción a cualquier persona que hubiera residido de forma efectiva con el causante durante los dos años anteriores a su fallecimiento (paliando con dicha limitación temporal los cambios de residencia fraudulentos a los únicos efectos de conseguir una menor tributación).

\section{EL REQUISITO DE CONVIVENCIA}

A pesar de las críticas ya apuntadas acerca de la exigencia del requisito de convivencia sólo a los colaterales mayores de 65 años (aparte de dejar fuera de la reducción tanto a los convivientes menores de dicha edad como a los que no guardaran ningún vínculo de parentesco con el causante), procede dedicar un especial análisis a cómo debe interpretarse dicha convivencia, especialmente por la cuestionable interpretación en unificación de doctrina también realizada por el TS.

Al respecto, como se ha señalado, la DGT ha sido siempre clara al establecer que, para que proceda la reducción del art. 20.2.c) de la LISD, el causante tenía que residir en la pertinente vivienda habitual de forma efectiva, negando su procedencia si se encontraba viviendo en un centro residencial o socio-sanitario ${ }^{28}$ o en la vivienda de una persona que le cuidara ${ }^{29}$.

Así, por lo que respecta a la necesaria convivencia que se exige a los colaterales mayores de 65 años para poder aplicar la reducción, se requiere que el causante y el adquirente tuvieran su residencia en una vivienda habitual común que perteneciera, al menos en parte, al propio causante, ya que, si no fuera así, no formaría parte del caudal relicto. En consecuencia, y a pesar de la independencia del título en virtud del cual cada uno de ellos habitara en la misma, esta convivencia no podía darse en la vivienda habitual del adquirente y entender que la que había sido la vivienda habitual del causante antes del traslado mantenía tal condición, ya que, como señaló la DGT, «la existencia de dos viviendas habituales impide la convivencia» ${ }^{30}$.

Sin embargo, la ya mencionada STS 841/2017, 12 de mayo, dictada en unificación de doctrina, también se pronunció al respecto, señalando que, como se ha visto, cuando concurriera alguna causa justificada (como puede ser la enfermedad), podrá aplicarse la reducción del art. 20.2.c) de la LISD aunque el causante hubiera trasladado su residencia por dicha razón al domicilio del colateral mayor de 65 años que resulte adquirente.

Por ello, no sólo declaró que el traslado desde la vivienda habitual de un causante a la de su hermano debido a motivos de salud no hizo perder a la primera tal condición, sino que también entendió que la convivencia producida en la vivienda habitual del hermano por más de dos años habilitaba a este último a aplicarse la reducción del art. 20.2.c) de la LISD (reconociéndole el derecho a la misma al adquirir la vivienda en la que había residido el causante antes de trasladarse).

Por consiguiente, las objeciones ya apuntadas respecto al concepto de vivienda habitual que realiza el TS por su incompatibilidad con el RIRPF resultan también aquí trasladables, sin olvidar que la finalidad de garantizar el derecho a disfrutar de una vivienda digna y adecuada que justifica la procedencia de la reduc-

28 A modo de ejemplo, véase la Resolución a la Consulta de la DGT 0672-03, de 20 de mayo.

29 Entre otras, véase la Resolución a la Consulta Vinculante de la DGT V0398-06, de 7 de marzo, donde se señala que, si la residencia habitual de la causante era en la vivienda de la adquirente, «no será aplicable la reducción porque la vivienda que se transmite no era la vivienda habitual de la causante, como exige el precepto, ya que tal condición de vivienda habitual -común a la causante y a la heredera-correspondía a la vivienda de la consultante, que no se transmite».

30 Resolución a la Consulta Vinculante de la DGT V0398-06, de 7 de marzo. 
ción implica, necesariamente, que el inmueble transmitido sea (y en principio vaya a ser) la vivienda habitual del adquirente (en el sentido de que no quede en riesgo por tener que hacer frente al pago de la pertinente cuota tributaria).

Y justamente por dicha finalidad, también resultan aplicables las alegaciones respecto a que, para la óptima viabilidad de la reducción, no deberían tenerse en cuenta ni los cambios de residencia temporales (como pueden ser los motivados por estudios o trabajo) ni aquellos permanentes de carácter forzoso (ya fueran de salud o por separación o divorcio), ya no sólo en relación con el causante sino también respecto a los adquirentes.

\section{EL MANTENIMIENTO DE LA VIVIENDA EN EL PATRIMONIO DEL ADQUIRENTE}

Finalmente, el último requisito que queda por analizar respecto a la aplicación de la reducción del art. 20.2.c) de la LISD es el condicionamiento de su procedencia a que la vivienda se mantenga en el patrimonio del adquirente durante los diez años siguientes al fallecimiento del causante, salvo que el mismo fallezca dentro de ese plazo. Sin embargo, como puntualizó el epígrafe 1.4.c) de la Resolución 2/1999, la Ley «no exige el destino de la misma como vivienda habitual del causahabiente», del mismo modo que, como ha reconocido reiteradamente la DGT, nada impide que pueda reinvertirse en otra vivienda que pase a tener o no el carácter habitual (siempre que la vivienda que se adquiera mantenga, al menos, el valor de adquisición de la que fue objeto de la transmisión mortis causa $)^{31}$.

En cualquier caso, como también ha puntualizado, la reinversión del valor en una nueva vivienda ha de llevarse a cabo de forma inmediata a la transmisión de la heredada (ya que debe mantenerse en el patrimonio del adquirente «durante» los diez años siguientes al fallecimiento «y no, por ejemplo, al término inicial y final de ese plazo»), correspondiendo al transmitente la acreditación de la materialización del importe de la enajenación de la vivienda adquirida por cualquier medio válido en Derecho (añadiendo, además, que nada obsta que el valor de adquisición para cada heredero se mantenga en una nueva vivienda distinta de la que adquiera el otro coheredero) ${ }^{32}$.

Asimismo, y teniendo en cuenta que la existencia permanente de una vivienda es lo que justifica la procedencia de la reducción ${ }^{33}$, nada impedirá tampoco que su valor se reinvierta en otra vivienda adquirida con anterioridad a la transmisión de la adquirida mortis causa, y ello con independencia del plazo de antelación (siempre que, como consecuencia de dicha reinversión, no disminuya el patrimonio del interesado) ${ }^{34}$, del mismo modo que parece que el importe obtenido con su transmisión también se podrá destinar a amortizar el préstamo o crédito hipotecario concedido al adquirente para la adquisición de su vivienda habitual (lo cual, precisamente, establece la normativa catalana de forma expresa al regular su propia reducción) ${ }^{35}$.

Además, procede destacar en este punto la excepción que al respecto se contempla en el caso Galicia, donde se señala que se permitirá el incumplimiento del requisito de permanencia si se transmitiese la vivienda en virtud de pacto sucesorio con arreglo a lo previsto en la Ley de Derecho Civil de la CCAA ${ }^{36}$. No obstante, sorprende en este caso que, a pesar de que también se permita la venta de la vivienda durante el plazo indicado, se supedite la reinversión de su importe a la adquisición de una vivienda ubicada en Galicia, la cual constituya o vaya a constituir la vivienda habitual de la persona adquirente.

$Y$ es que, como ya se ha señalado, el territorio resulta un elemento de discriminación carente de justificación alguna ante situaciones objetivamente comparables, motivo por el cual vulnera los principios constitucionales de igualdad e igualdad tributaria junto con el deber general de contribuir. Asimismo, en este caso, la

31 Resoluciones de las Consultas Vinculantes de la DGT V0202-04, de 14 de octubre, y V0717-06, de 12 de abril.

32 Resolución de la Consulta Vinculante de la DGT V1021-06, de 31 de mayo.

33 Al respecto, señala la Resolución de la Consulta Vinculante de la DGT V2590-06, de 27 de diciembre, que, atendiendo al sentido usual de los términos conforme al artículo 12.2 de la LGT, «ha de entenderse que la reinversión del valor en una nueva vivienda ha de llevarse a cabo de forma inmediata a la transmisión de la heredada, inmediatez que deriva del hecho de que el beneficio fiscal está condicionado tanto al mantenimiento del valor como de la existencia permanente de una vivienda, que es lo que justifica precisamente la procedencia de la reducción en el impuesto».

34 Resolución de la Consulta Vinculante de la DGT V0717-06, de 12 de abril.

35 Art. 19 de la Ley 19/2010, de 7 de junio, de regulación del Impuesto sobre Sucesiones y Donaciones, en la que se establece un plazo máximo de seis meses desde la fecha de transmisión de la vivienda habitual del causante hasta la reinversión en una nueva vivienda o hasta la mencionada amortización.

${ }^{36}$ Art. 7.tres. 2 del Decreto Legislativo 1/2011, de 28 de julio, por el que se aprueba el Texto Refundido de las disposiciones legales de la Comunidad Autónoma de Galicia en materia de tributos cedidos por el Estado. 
REALA. Nueva Época - N.o 11, Abril-Septiembre 2019 - ISSN: 1989-8975 - DOI: 10.24965/reala.v0i11.10574 - [Págs. 122-138]

La reducción en el ISD por la adquisición de la vivienda habitual del causante: análisis estatal, autonómico y foral

Irene Rovira Ferrer

previsión gallega supone un claro atentado al derecho a la libre elección de residencia reconocido en el art. 19 de la CE, e incluso de los principios de libertad de circulación de capitales y personas en los que se fundamenta la UE. Y por si fuera poco no hay que olvidar que el art. 48 de la Ley 22/2009 únicamente permite que las CCAA regulen las reducciones de la base imponible del ISD previstas por el Estado si es para su mejora, lo que no ocurre notoriamente en este caso al implicar una clara restricción (ya no sólo por el elemento territorial sino porque la LISD no exige que el nuevo inmueble se convierta en la vivienda habitual del adquirente).

De todos modos, si el requisito de permanencia deja de cumplirse en cualquier caso, el adquirente deberá comunicarlo a la Administración tributaria competente en el plazo de 30 días desde que el incumplimiento tenga lugar (mediante una autoliquidación complementaria si había autoliquidado el Impuesto) ${ }^{37}$, satisfaciendo al mismo tiempo la parte de la cuota tributaria dejada de ingresar como consecuencia de la reducción practicada y los correspondientes intereses de demora.

No obstante, y a pesar de que la transmisión de la vivienda adquirida para su inversión en otra se admita expresamente, también debería permitirse el incumplimiento de este requisito debido a la difícil situación económica en la que puedan encontrarse los adquirentes, como puede ser en el caso de que la pierdan por su dación en pago o su ejecución hipotecaria, judicial o notarial, para la cancelación de deudas con entidades de crédito o equivalentes garantizadas con hipoteca que recaiga sobre la misma.

De hecho, justamente cuando dichas transmisiones tengan lugar respecto a la vivienda habitual del deudor hipotecario o del garante del mismo, el art. 105.1.c) del Texto Refundido de la Ley Reguladora de las Haciendas Locales, aprobado por el Real Decreto Legislativo 2/2004, de 5 de marzo, exonera del pago del Impuesto sobre el Incremento de Valor de los Terrenos de Naturaleza Urbana por la manifiesta ausencia de capacidad económica de los sujetos pasivos, por lo que no tendría mucho sentido que, operando las mismas razones, se les reconozca tal exoneración pero deban hacer a la parte de la cuota tributaria dejada de ingresar por la aplicación de la reducción en el ISD junto con los correspondientes intereses de demora (y más considerando que la fundamentación de la misma viene amparada, al menos en parte, por el derecho a una vivienda digna y adecuada).

En cualquier caso, y a pesar de que dicho plazo de mantenimiento haya sido rebajado por todas las autonomías que han regulado la reducción (fijándose mayoritariamente en 5 años excepto en los casos de Andalucía y el Principado de Asturias, que es de 3), cierto es que, considerando las finalidades que justifican la procedencia reducción, carece de todo sentido, pudiendo resultar incluso contrario a la protección del derecho a disfrutar de una vivienda digna y adecuada reconocido en el art. 47 de la CE (ya que, además de influir en las decisiones económicas de los ciudadanos -vulnerando, en consecuencia, el principio de neutralidad fiscal-, viene a restringir la oferta del mercado inmobiliario).

Asimismo, al no exigirse que la vivienda transmitida también fuera la vivienda habitual del adquirente, el requisito de permanencia tampoco puede justificar que éste pueda beneficiarse de la reducción de tantas viviendas habituales como adquiera (con la consiguiente vulneración del principio de generalidad, la clara discriminación de la adquisición mortis causa de otras formas de riqueza y la de aquellas personas que, por su menor capacidad económica, no pudieron obtener una vivienda en propiedad), por lo que no es de extrañar que la Comisión de Expertos para la reforma del Sistema Tributario propusiera directamente la eliminación de la reducción aquí estudiada (aunque dejándola únicamente para el cónyuge supérstite) ${ }^{38}$.

$Y$ es que, si lo que realmente se desea es beneficiar la adquisición mortis causa de los familiares directos, se puede conseguir igualmente por otras vías menos conflictivas, como son las específicas reducciones a la base imponible por dicha causa, los especiales coeficientes multiplicadores para obtener su cuota tributaria o incluso, si se considera necesario, mediante el establecimiento de reducciones en la propia cuota.

No obstante, si lo que realmente se pretende es la protección del derecho contemplado en el art. 47 de la CE, debería reconocerse la reducción a todos aquellos sujetos que hubieran convido con el causante durante los dos años antes de su fallecimiento (con independencia de su edad y de su vínculo de parentesco), tal y como hacen los territorios históricos forales del País Vasco con carácter general.

Y todo ello sin olvidar que, como destaca De PABLo (2009), también debería protegerse el mencionado derecho en el caso de las adquisiciones lucrativas inter vivos (ya que, en principio, la necesidad real

${ }^{37}$ Art. 137.3 del Real Decreto 1065/2007, de 27 de julio, por el que se aprueba el Reglamento General de las actuaciones y los procedimientos de gestión e inspección tributaria y de desarrollo de las normas comunes de los procedimientos de aplicación de los tributos.

38 Propuesta núm. 55 del Informe de la Comisión de Expertos para la reforma del Sistema Tributario, de febrero de 2014, publicado por el Ministro de Hacienda y Administraciones Públicas, pág. 252, a la que se remite el Informe de la Comisión de Expertos para la revisión del modelo de financiación autonómica, de julio de 2017, publicado por el Ministro de Hacienda y Función Pública, pág. 57. 
REALA. Nueva Época - N.o 11, Abril-Septiembre 2019 - ISSN: 1989-8975 - DOI: 10.24965/reala.v0i11.10574 - [Págs. 122-138]

La reducción en el ISD por la adquisición de la vivienda habitual del causante: análisis estatal, autonómico y foral

Irene Rovira Ferrer

de vivienda del heredero se dará en su juventud y no cuando tenga lugar el fallecimiento de sus padres), añadiendo RozAs (2012) en la misma línea la mayor productividad de favorecer el trasvase de bienes a las generaciones más jóvenes en lugar de paralizarlos en el patrimonio de las generaciones más ancianas.

\section{CONCLUSIONES}

Considerando que la adquisición mortis causa de los familiares directos, con base en el art. 39 de la CE, puede encontrarse protegida en el ISD por otras medidas tributarias (como son las específicas reducciones a la base imponible por dicha causa o los especiales coeficientes multiplicadores para obtener la cuota tributaria -sin perjuicio de que, si se considera necesario, incluso puedan establecerse reducciones a la propia cuota-), la correcta configuración de la reducción de la base imponible por la adquisición de la vivienda habitual del causante debería buscarse únicamente en la protección del derecho a disfrutar de una vivienda digna y adecuada (art. 47 de la CE), replanteando, en consecuencia, su configuración con base en dicha finalidad (lo que, además de aportar una mejora importante en sentido técnico, simplificaría en gran medida la gestión del Impuesto).

Por consiguiente, tal y como han hecho en los territorios históricos forales del País Vasco, lo más correcto sería reconocerla a los sujetos que hubieran residido de forma efectiva con el mismo durante los dos años anteriores a su fallecimiento (dificultando así los cambios de residencia fraudulentos a los efectos de conseguir una menor tributación), prescindiendo de este modo del vínculo de parentesco que existiera entre sí y de la edad del adquirente.

Así, además de quedar justificada la diferencia de trato respecto a la adquisición de otras formas de riqueza, se acabaría con la discriminación que actualmente padecen aquellos sujetos que resultan excluidos respecto de aquellos que, encontrándose en idénticas circunstancias e incluso sin haber conviviendo con el causante, sí que se les reconoce (como puede ser el caso de los miembros de las uniones estables de pareja, en relación con los cónyuges, en aquellas CCAA donde no se hayan reconocido), sino que también se eliminarían las cuestionables previsiones autonómicas al respecto susceptibles incluso de inconstitucionalidad (como ocurre con la exclusión de los parientes colaterales por afinidad en el caso de Galicia).

Además, al exigirse la convivencia previa, también podría eliminarse el requisito del mantenimiento de la vivienda en el patrimonio del causante, terminando, en consecuencia, con los lamentables efectos que conlleva (dejando de influir en las decisiones económicas de los ciudadanos -y respetando, en consecuencia, el principio de neutralidad fiscal-, acabando con restricción de la oferta del mercado inmobiliario que comporta y terminando con la difícil justificación de que el adquirente pueda beneficiarse de la reducción de tantas viviendas habituales como adquiera -con la consiguiente desproporcionalidad del beneficio fiscal, la vulneración del principio de generalidad y la clara discriminación de la adquisición mortis causa de otras formas de riqueza).

Asimismo, se acabaría con la exigencia de Galicia de que, si se reinvierte la vivienda adquirida, sea en una vivienda que constituya o vaya a constituir la vivienda habitual del adquirente y que se encuentre ubicada en su territorio, la cual, como también se ha puesto de manifiesto, es asimismo susceptible de inconstitucionalidad.

No obstante, sería necesario eliminar de forma expresa la limitación de la procedencia de la reducción que hace Canarias al señalar que la vivienda habitual del causante debe estar radicada dentro de su territorio (lo que, además de poder resultar contrario a la CE, puede vulnerar los derechos y libertades provenientes del Derecho europeo), del mismo modo que, para mejorar la gestión del Impuesto, sería deseable que cuanto menos se especificaran los elementos vinculados con el concepto de vivienda habitual que pueden quedar incluidos en la aplicación de la reducción (trasteros, plazas de aparcamiento, etc.).

Finalmente, con el fin de evitar discriminaciones injustificadas y tutelar de forma efectiva el derecho del art. 47 de la CE, no deberían tenerse en cuenta los traslados permanentes de carácter forzoso (como podrían ser los de salud) ni aquellos temporales por motivos justificados (como pueden ser de trabajo o de estudios), tanto por lo que respecta al causante como en relación con el propio adquirente.

Sin embargo, procede recordar por último que la plena garantía del derecho a disfrutar de una vivienda digna y adecuada pasa también por abordarse en mayor medida dentro del Impuesto sobre Donaciones, y es que suelen ser las generaciones más jóvenes las que más ayuda necesitan para poder acceder a una vivienda habitual. 


\section{BIBLIOGRAFÍA}

ÁLVAREZ BARBEITO, P. (2010): "Doctrina administrativa y jurisdicional sobre la reducción por adquisición mortis causa de la vivienda habitual del causante", en Estudios financieros. Revista de contabilidad y tributación: Comentarios, casos prácticos, núm. 329-330.

CALVO VÉRGEZ, J. (2008): "La reducción por adquisición mortis causa de la vivienda habitual del causante en el Impuesto sobre Sucesiones: análisis de las principales cuestiones suscitadas a la luz de la reciente doctrina administrativa", en Quincena Fiscal, núm. 18.

COMISIÓN DE EXPERTOS PARA LA REFORMA DEL SISTEMA TRIBUTARIO (2014): Informe de la Comisión de Expertos para la reforma del Sistema Tributario, de febrero de 2014, Ministro de Hacienda y Administraciones Públicas, Madrid.

COMISIÓN DE EXPERTOS PARA LA REVISIÓN DEL MODELO DE FINANCIACIÓN AUTONÓMICA (2017): Informe de la Comisión de Expertos para la revisión del modelo de financiación autonómica, de julio de 2017, publicado por el Ministro de Hacienda y Función Pública, Madrid.

CONSULTAS OFICINAS LIQUIDADORAS (2007): "Mantenimiento de la vivienda habitual del causante en el patrimonio de los herederos", en OL. Revista Tributaria Oficinas Liquidadoras, núm. 4.

CONSULTAS OFICINAS LIQUIDADORAS (2007): "Mantenimiento del derecho a la aplicación en el Impuesto sobre Sucesiones y Donaciones de la reducción estatal por adquisición de la vivienda habitual del causante en el supuesto de segregación de la citada vivienda y posterior adjudicación a los herederos", en OL. Revista Tributaria Oficinas Liquidadoras, núm. 8.

CARO ROBLES, V. (2001): "La transmisión de la empresa familiar y de la vivienda habitual en el Impuesto sobre Sucesiones y Donaciones", en Revista de Contabilidad y Tributación, núm. 223.

DE PABLO VARONA, C. (2009): "La protección del derecho a una vivienda digna en la imposición sobre la renta (IRPF e ISD)", en ARRANZ DE ANDRÉS, C. y SERNA VALLEJO, M. (eds.): Estudios de Derecho Español y Europeo. Santander: Universidad de Cantabria.

FALCÓN Y TELLA, R. (1999): "Las reducciones en la base imponible del Impuesto sobre Sucesiones y Donaciones en materia de vivienda habitual y empresa familiar: el discutible criterio de la Dirección General de Tributos”, en Quincena Fiscal, núm. 8.

GARCÍA DE PABLOS, J. F. (2001): "El Impuesto sobre Sucesiones y Donaciones: supresión o reforma”, en Crónica Tributaria, núm. 139.

GARCÍA DE PABLOS, J. F. (2010): El Impuesto sobre Sucesiones y Donaciones en España. Cizur Menor: Aranzadi.

MARTÍN QUERALT, J., LOZANO SERRANO, C., CASADO OLLERO, G. y TEJERIZO LÓPEZ, J. M. (2000): Curso de Derecho Financiero y Tributario. Madrid: Tecnos.

ROZAS VALDÉS, J. A. (2012): "La vivienda en el Impuesto sobre sucesiones y donaciones" en VARONA ALABERN, J. E. (coord.): La fiscalidad de vivienda en España. Madrid: Civitas-Thomson Reuters.

VARONA ALABERN, J. E. (2014): "Razones necesarias para la rehabilitación y la necesaria reforma del impuesto sobre sucesiones y donaciones", en Quincena Fiscal, núm. 16. 